\title{
INLEIDING TOT DE THEOLOGIE VAN E. BRUNNER (vervolg)
}

\section{HET AANKNOPINGSPUNT}

Het gaat Brunner erom, dat de werkélijke levende God komt tot de wérkelijke mens en die mens dan ook bereikt. Van het door de Openbaring Gods uit bepaalde denken is het, dat Brunner theologische belangstelling krijgt voor het raadsel mens: hoe zal de Openbaring Gods de mens bereiken? is er bij de mens voor het spreken Gods een anknopingspunt? Brunner ziet in de Bijbel, speciaal in Rom. 1:19, 20 en 2:14, 15 een duidelijke aanwijzing van de werkelijkheid der algemene openbaring en hij schrijft hierover in 1934 zijn brochure „Natur und Gnade"-want hij meent, dat aan de uit deze openbaring voortvloeiende menselijke verantwoordelijkheid tegenover God in de Zwitserse theologie wordt tekort gedaan. Wat Brunner in het kort met deze brochure wil zeggen verklaart hij in een voorwaarde met de volgende plaats van Luther: "W'anneer de natuurlijke wet Gods niet door God in het hart geschreven was, zou men lang moeten prediken voordat de gewetens getroffen werden - tot een os en een ezel wel honderdduizend jaar! Waarom? wat ontbreekt er? Hun ziel is er niet naar geschapen, dat zulks daarin valt. Maar een mens, zo gauw hem de wet wordt voorgehouden, zegt: $\mathrm{ja}, z \mathrm{o}$ is het. Daarvan zou men hem niet zo gauw kunnen overtuigen, als deze hem niet tevoren in het hart was geschreven. Omdat zij tevoren al in zijn hart is, hoe verdonkerd ook, wordt het door het Woord weder opgewekt". Evenals Luther hier gaat het ook Brunner erom, dat de gewetens getroffen worden. En wanneer Brunner dan ook het aanknopingspunt in de mens voor het Woord Gods formuleert als de ook bij de zondaar niet verloren gegane formele imago Dei, formeel beeld Gods, bestaande uit het eenvoudige mens-zijn, waardoor hij in staat is, dit Woord te horen en in verantwoordelijkheid daartegenover te beslissen, dan legt hij dit accent, opdat wij juist bij het werk onder hen, die buiten de kerk staan, zullen weten van hun verantwoordelijkheid t.a.v. de boodschap, die wij hen brengen. Waarbij Brunner echter, geheel bijbels, de beperking maakt, dat deze aanspreekbaarheid van de mens zuiver formeel is en niet materieel, alsof de mens als zodanig al zou kunnen geloven. „Das ist der Anknüpfungspunkt: Wortmächtigkeit und Verantwörtlichkeit". En op zeer heldere wijze wordt dit standpunt gegrond op ontelbare plaatsen bij Calvijn.

\section{Conflict Brunner-Barth.}

Het is tegen Brunners brochure "Natur und Gnade", waarin Brunner om 's mensen verantwoordelijkheid wille pleit voor het formele aanknopingspunt in de mens voor het spreken Gods, dat Karl Barth zijn krachtig „NEIN!” (titel van zijn antwoord aan Brunner) laat horen, waardoor het uit elkaar gegroeid zijn van Brunner en Barth nu aan de gehele theologische wereld openbaar wordt. 
In zijn „NEIN! Antwort an Emil Brunner” wijst Barth op een voor zeer velen onbegrijpelijk felle wijze Brunners gedachtenwereld af. Historisch is deze felheid te verklaren uit het feit, dat Barth in deze tijd zeer in de Duitse kerkstrijd betrokken raakt (te meer, omdat hij zijn oude medestander Gogarten aan het nationaal-socialisme verloren heeft), in welke strijd hij voortdurend te maken heeft met de vergoddelijking van het geschapene, waarom hij an alle te zeer waarde hechten aan wat tot de mens behoort een radicaal einde gemaakt wil zien. Voortdurend heeft hij te vechten tegen de verabsolutering van ordeningen als bloed, volk en ras en wordt hij daardoor fel gebeten op alles, wat naar natuurlijke theologie zweemt, waarbij ook Brunner een veeg uit de pan krijgt. Maar dan is Barth in dit opzicht wel aan het verkeerde adres, omdat Brunner het aanknopingspunt voor het spreken Gods in de mens evenals de Reformatoren zuiver formeel wil zièn en overigens in het verzet tegen het Deutschchristentum even fel is als Barth. Het is niet voor niets geweest, dat al heel spoedig na het aan de macht komen van het nationaal-socialisme Brunners boeken in Duitsland en in bezettingstijd ook in Nederland verboden en in de papiermolen gedraaid zijn!

Toch - hoe vreemd dit ook moge klinken - geloof ik, hoe fel Barths reactie op Brunners „Natur und Gnade” ook geweest moge zijn, niet, dat hier het grootste verschil ligt tussen Brunner en Barth. Het is dan ook opvallend, dat Brunner in het eerste deel van zijn Dogmatik gaarne instemt met wat Barth in zijn Dogmatik 3-1 „Die Lehre vond der Schöpfung" over natuurlijke theologie zegt! Ook Barth moet immers in de formele zin, waarin Brunner dit doet, wel een aanknopingspunt erkennen - en Barths tegenwerping, dat Calvijn op grond van de historische situatie zijner dagen nog niet aan een fel protest tegen natuurlijke theologie toe was, is, gezien de zeer véle plaatsen, waarin Calvijn in zijn Institutie over scheppingsopenbaring spreekt en die door Brunner worden aangehaald, toch wel héel mager! Het twistpunt op zichzelf daargelaten kan een beoordelaar wel tot geen andere conclusie komen, dat, wat de Reformatoren betreft, Brunner in zijn brochure meer in de reformatorische lijn denkt dan Barth doet!

\section{het Werk van de Heilige Geest.}

Groter verschil dan in de kwestie van het anknopingspunt, ook al heeft het hier natuurlijk wel verband mee, zie ik persoonlijk in de leer aangaande de Heilige Geest, waarover Brunner in 1935 zijn voortreffelijk boekje „Vom Werk des Heiligen Geistes” (in 1945 gevolg door „Die Lehre vom Heiligen Geiste") publiseert. Om tot de draad van een vorige maal terug te keren: het gaat Brunner in zijn theologie om de doorbraak van de werkelijke, levende God in de werkelijke wereld - en die doorbraak gaat door, ook tot in het diepst van de menselijke ziel. Daarom wijdt Brunner dit boekje aan het beschrijven van wat de Heilige Geest in het leven van de mens, die door Gods Woord werd getroffen, doet: Hij 
schenkt ons voor het verleden geloof in Gods vergeving; voor het heden een verbreking van het harde en koude IK, zodat dit open wordt voor liefde tot de naaste; voor de toekomst hoop, dat die vernieuwing, die in de zonde-gebrokenheid van deze wereld nog maar ten dele is, totaal zal zijn in het eeuwige Rijk Gods, dat komt (vgl. 1 Cor. 13:13). Hier is voor mijn gevoel het verschil met Karl Barth, die de werking des $\mathrm{H}$. Geestes in het mensehart veel minder zichtbaar-reëel ziet, groter, dan ten aanzien van de leer van het aanknopingspunt.

\section{Ontmceting met de Groepbeweging.}

Ik zie Brunners visie aangaande het werk van de Heilige Geest mede als gevolg van diens ontmoeting met die Groepbeweging, die in deze jaren plaatsvindt. Ondanks alle critiek, die, soms terecht, soms ook ten onrechte, op de Oxford-Groep is uitgeoefend, moet ieder, die er middenin heeft gestaan, toch wel erkennen, dat hier soms sprake is geweest van een zeer reëel en krachtig werk van de Heilige Geest. In de Groep zijn honderdtallen, om niet te zeggen duizendtallen mensen uit het witte heidendom, die van Christus niet wisten en zich van het woord Drieëenheid afvroegen (zoals ik self meemaakte!), of dit nu geloof, hoop en liefde of moed, beleid en trouw betekende, veranderd tot zeer levende getuigen van de Heer. En omdat Brunner ondanks die grote reserves, die er ook bij hem bestonden, niet op een theologische afstand is blijven staan, maar zich er middenin heeft gegooid, heeft hij zelf de persoonlijke zegen, aan veler contact met de Groep verbonden, ook ervaren (zoals hij in het voorwoord voor $\mathrm{H}$. J. Rinderknecht's boekje „Vier brieven van het nieuwe leven" schrijft), en heeft in het, altijd sterk Christocentrische, Zwitserse Groep-team meer en meer de vreugde leren kennen, wat het is, mede-arbeider Gods te zijn. In 1936 verschijnt zijn, ook in het Nederlands vertaalde, „De kerken, de Groepbeweging en de Kerk van Jezus Christus", waarin hij een bijbels verantwoord beeld geeft van de grondbeginselen der Groepbeweging, dat ook speciaal voor de Groepen over over de gehele wereld van grote betekenis is geweest als wachter tegen fouten, die op elke levende weg steeds weer dreigen. Het is hier, dat Brunner het doorbreken van de Heilige Geest in mensenharten steeds opnieuw heeft meegemaakt, zodat zijn leer over de Heilige Geest voor hem geillustreerd wordt door dat, wat hij persoonlijk van het werk van die Geest heeft gezien.

Het is Brunner in zijn theologisch denken erom te doen, dat de werkelijke, levende God doorbreekt in de wereld tot in het leven van de werkelijke mens. Vanuit deze lijn gezien past de Groepbeweging, welker kernwoorden immers zijn: overgave, stil-zijn voor God, leiding, delen, rentmeesterschap, geheel in de lijn van Brunners ontwikkeling. Maar Brunner is er niet te groot voor, ook zelf te erkennen, hoeveel hij aan de Groepbeweging te danken heeft. Op een grote samenkomst in Utrecht zei hij eens: „Ik kom uit het kamertjie naast het podium, waarop een bord staat: 
Alleen voor solisten. Daar hoorde ik vroeger ook; zo'n solist was ik. $\mathrm{Nu}$ heeft God mij echter in de gemeenschap gesteld". Juist omdat hij zelf veel aan deze beweging te danken heeft gehad, heeft het hem echter pijn gedaan, dat de Groep, onder invloed van een verkeerde, Angelsaksische, Koninkrijk-Gods-theologie, soms verzeilen ging in humanistisch wereldverbeterende wateren. In 1947 schreef Brunner mij: „Sedert vele jaren heb ik mij uit de Oxford-Groep teruggetrokken, omdat ik innerlijk niet meer mee kon ... In de laatste tijd heb $\mathrm{ik}$ mij echter weer veel positiever ingesteld, omdat ik gezien heb, dat zij onder het programma der Morele Herbewapening in werkelijkheid een evangelisatiearbeid verricht als wel geen andere Chr. groep of kerk. Er zijn echter vele principiële vragen, waarop ik tot nu toe geen ontwoord ontving: t.a.v. de Koninkrijk-Gods-Theologie, de MRA-ideologie, het samenwerken met Mohammedanen enz. Daarom kan er geen sprake van zijn, dat ik mij met haar identificeer. Anderzijds ben ik van het belang van de arbeid der Morele Herbewapening (zoals de Groep zicht tegenwoordig noemt) overtuigd". Toch blijft hij ook in het derde deel van zijn Dogmatik, dat in 1960 verscheen, zéer positief over MRA oordelen. Mét de reserve, die hij heeft, blijft hij zeggen: Toch is Gods Geest hier aan het werk".

\section{BrunNeRs BIJBELBESCHOUWING.}

Wij snijden nu een geheel ander onderwerp aan als we enkele woorden zeggen over Brunners Bijbelbeschouwing. Wanneer wij ook hier de lijn volgen, die wij in het voorafgaande zagen; dat het Brunner in zijn theologie erom gaat, dat de werkelijke, levende God doorbreekt tot in het leven van de werkelijke mens, past hierbij, dat hij ook bereid is, alle menselijke belemmeringen, voorzover principieel mogelijk, uit de weg te ruimen opdat de grote ontmoeting tussen God en mens maar onbelemmerd plaatsvindt! In een stelling bij zijn pas in Utrecht verdedigd proefschrift schrijft uw Dr. A. J. G. Dreyer: „Die aanspraak op die onfeilbaarheid van die Skrif stimuleer nie die geloof nie, maar vernietig dit". Brunner zou dit geschreven kunnen hebben! Daar hij weet, dat verschillende mensen echt zitten met bijbelgedeelten, die b.v. niet in het moderne wereldbeeld passen, beschouwt hij het mede als zijn ook in het Nederlands vertaalde boekje: „Het Woord Gods en de moderne mens” uit 1937, waarin het hoodfstuk „Het scheppingsgeloof en het wetenschappelijk wereldbeeld" is opgenomen. Duidelijk toont Brunner hierin aan, dat de Bijbel niet bedoelt een leerboek voor geschiedenis en aardrijkskunde of geologie te zijn (hebben de auteurs der bijbelboeken niet gewerkt met het wereldbeeld van hun tijd, waarin de aarde beschouwd werd als een plat vlak, terwijl de zon om de aarde zou draaien inplaats van omgekeerd?), maar een boek, dat in de taal en gedachtenwereld der Bijbelschrijvers getuigenis aflegt van Gods openbaring.

En ik denk hier ook aan het in vele talen vertaalde catechisatieboek „Ons Geloof", dat in zijn Nederlandse uitgave al een achtste druk beleefde, en 
een uitnemend middel is, buiten- en binnenkerkelijken in de Bijbelse gedachtewereld in te leiden. Zoals wij ook reeds in het gedeelte over de maagdelijke geboorte in „der Mittler” zagen, is Brunner geheel bereid waar dit nodig en mogelijk is stukken Bijbelse bast te laten vallen opdat de kern der Bijbelse boodschap: Jezus Christus, de Gekruisigde en Opgestane, maar duidelijk de moderne mens zal bereiken. Ik denk aan het beeld van de gramofoonplaat: zoals je bij het draaien daarvan de muziek hoort, maar ook soms bijgeluiden, zo hoor je in de Bijkel de stem Gods, maar ook de menselijke bijgeluiden der schrijvers, die kinderen waren van hun omgeving, hun tijd, en de wetenschappelijke inzichten hunner dagen.

\section{ZIJN RÖMERBRIEF.}

Omdat Brunners leeropdracht in Zürich allereerst de dogmatische, ethische en practische vakken betrof, is het wel vanzelfsprekend, dat er op specifiek uitlegkundig gebied weinig van hem verschenen is. $W_{i j}$ vinden van hem slechts éen commentaar, maar dat is dan ook de in 1938 in de serie „Bibelhilfe für die Gemeinde" uitgekomen commentaar op de brief aan de Romeinen, waarmee vele dogmatici zich op éen of ander punt van hun loopbaan hebben bezig gehouden! Ik denk aan Barths Römerbrief, die, nu enigszins verouderd, destijds grote aandacht trok als éen der eerste diepgaander uitingen van de z.g. Zwitserse theologie. Brunners korte commentaar "der Römerbrief" is vooral van belang om de correcties, die hij hierin op Bijbelse grondslag in Barths werk aanbrengt, speciaal in de eerste hoofdstukken ten aanzien van de leer der natuurlijke Godskennis (die Brunner tot op zekere hoogte met nadruk wil handhaven om de mens niet zijn verantwoordelijkheid voor de geloofsbeslissing te ontnemen) en de z.g. onzichtbare vruchten van het werk van de H. Geest, waarover hij, zich als over ,de nieuwe ontdekking op dit gebied" zacht ironisch uitlaat! De Bijbel bedoelt toch wel degelijk te zeggen, dat er door het werk des $\mathrm{H}$. Geestes inderdaad iets in de mens verandert, wat ook naar buiten doorwerkt (vgl. Matth. 7: 17-19 etc. en Vr. en Antw. 86 Heid. Cat.). Aan het slot van deze commentaar behandelt Brunner dan enkele kernwoorden, die dikwijls in deze brief ter sprake komen, als Heiliging, Liefde, Uitverkiezing, Rechtvaardiging van de zondaar, Doop, Toorn Gods, Geest-Vlees en Verzoening. De behandeling dezer kernwoorden werpt nieuw helder licht op de Romeinenbrief.

\section{Een Zeer Belangrijk Werk.}

In ditzelfde jaar 1938 (waarin ook nog de prekenbundel Saat und Frucht verschijnt, die op zeer aansprekende wijze tien gelijkenissen in preekvorm behandelt) ziet de bundeling het licht van zes lezingen, in de herfst van 1937 aan de Zweedse universiteit Uppsala gehouden, over de verhouding van het objectieve en het subjectieve in het Christendom. Deze bundel, „Wahrheit als Begegnung”, is m.i. éen van de allerbeste werken, die Brunner ooit heeft geschreven. Ik kan dan ook niet meegaan 
met het oordeel van Eduard Thruneysen, die in zijn „Kreuz und Wiederkunft Christi" dit werk van Brunner wel zeer prijst, maar tenslotte toch als zijn oordeel uitspreekt: ,een hoger soort piëtisme dan het normale”, wat in zijn kring nogal een vloek betekent! Neen, ik geloof integendeel, dat Brunner in deze lezingen op een juiste manier heen komt over de zo dikwijls in de kerkgeschiedenis voorgevallen tegenstelling tussen objectivisme en subjectivisme door de Bijbelse waarheid te bezien als waarheid als ontmoeting, bij welke ontmoeting het accent zowel valt op het souvereine handelen van de Almachtige en Genadige God als op het geloofsantwoord van de geroepen mens. Hierin geeft Brunner dan tevens een correctie op de op sommige punten z.i. té objectivistische strekking van zijn eigen in 1927 verschenen boek „Der Mittler”. Ten aanzien van de door Barth later aan de theologische orde gestelde kwestie van de kinder doop is hier interessant, dat Brunner vanuit zijn ,W'ahrheit als Begegnung"-gedachte degeldende Doopspractijken reeds in 1938 als ,,skandalös" beschouwde! Brunner wil echter niet de kinderdoop laten vallen, maar evenmin de doopsgewoonte, waarbij practisch bijna alles gedoopt wordt, handhaven; hij wil terugkeren tot de Bijbelse lijn, volgens welke de gelovingen, die dus antwoord hebben gegeven op Gods roep, gedoopt worden met hun huis (Hand. 16: 33, vgl. 1 Cor. 1: 16). Geen verwerping van de kinderdoop dus, maar evenmin een ,alles dopen, wat in het doophuis komt". Een discussie met de Nederlandse theoloog A. A. van Ruler, die de gehele Europees-Amerikaanse (en dus ook Suid-Afrikaanse) cultuur gestempeld ziet door het christendom en daarom min of meer meent, dat alle kinderen gedoopt kunnen worden omdat $z \mathrm{ij}$ in elk geval aan deze cultuur deel krijgen, zou zeer belangwekkend kunn^n zijn!

\section{Amerika.}

Het is nodig, hier de volgorde van Brunners werken even te onderbreken met een biografische notitie. In 1938 vertrekt Brunner voor een jaar naar Amerika om daar op uitnodiging colleges te geven aan de Princetown-universiteit, die vanouds om haar fundamentalistische gezindheid bekend staat! Daar jaagt hij af en toe zijn hoorders de stuipen op het lijf met zijn enerzijds zeer reformatorisch georiënteerde colleges, die echter anderzijds duidelijk getuigen van de reeds omschreven Bijbelbeschouwing! $\mathrm{Na}$ dit jaar keert hij dan naar Zürich terug, waarheen tevens zijn sterk vaderlandslievend hart hem trekt met het oog op de komende politieke crisis.

\section{Strijd tegen het NationaAlsocialisme.}

Vanzelfsprekend wordt in het Zwitserland dezer jaren zijn denken zeer in beslag genomen door de grote strijd, die staat uit te breken tussen het Duitse nationaal-socialisme en de democratisch geregeerde landen. Hoe Brunner in deze strijd zou staan, was al genoeg bekend: had hij niet een bevel geweigerd, bepaalde gedeelten uit „Das Gebot und die Ord- 
nungen" terug te nemen en waren daarom niet al zijn vele boeken in Duitsland als straf door de papiermolen gedraaid? Had hij niet in 1938 ook „Die Machtfrage” gepubliceerd, een wel zeer scherpe aanval op het nationaal-socialisme? Getuigden niet al zijn boeken van de werkelijkheid van Gods betrekking tot deze aarde, waarvan $\mathrm{Hij}$ de totale souvereine Heer is - niet te aanvaarden voor een ideologie, die zelf de aarde opeist en God, indien Hij nog gewenst wordt, naar de ziel en de hemel verbant?

Op verzoek van de Zwitserse opperbevelhebber, generaal Guisan, schrijft hij in 1940 voor het gemobiliseerde Zwitserse leger de brochure "Eiserne Ration" - Noodrantsoen - , opdat de soldaten weten, waarwaarvoor en waarmee zij leven en sterven kunnen. In dat zelfde jaar bewijst hij de Zwitserse kerk dezelfde dienst als Kraemer in 1940 de Nederlandse begon te bewijzen door de publicatie van zijn „Vom Lage und Aufgabe der Kirche in der Gegenwart", waarin hij de kerk oproept tot werkelijk kerk-zijn op alle terreinen des levens, mede, omdat alleen een kerk, die ernst maakt met haar van Godswege geroepen zijn, in staat is, staande te blijven temidden van alle woede wereldstormen. Die inhoud van deze brochure is zeer verwant aan de in deze jaren in Nederland door Kraemer, Gravemeyer en Banning gepubliceerde Gemeente-Opbouwgedachten, die een vernieuwing der kerk van binnen uit beogen, en welke ook voor de kerken in Suid-Afrika van groot belang zijn. Mogen zij nog meer onder uw aandacht komen! - En in deze jaren, waarin de grondslagen onzer cultuur ontzaglijk geschud hebben, behandelt Brunner in 1941 de grondslagen der Westerse cultuur in zijn boek „Offenbarung und Vernunft", waarin hij vele resultaten van zijn vroegere theologische onderzoekingen neerlegt en deze tot een verantwoorde eenheid samenvoegt. Als zodanig geeft dit boek een waardevol beeld van Brunners gedachtenwereld op zeer verschillende terreinen. Hierop laat hij dan in 1943 zijn ook in het Nederlands verschenen boek "Gerechtigheid" volgen, waarin hij grondslagen poogt te leggen voor de komende naoorlogse ordening, voortvloeiende uit het reformatorische denken. Hij gaat hier o.a. in op de probelmen van de ordeningen gezin en maatschappij, (waarbij hij o.a. het dwangcommunisme afwijst), staat en volkeren. Het schilderen van een positieve, rechtvaardige mogelijkheid is de beste afweer tegen het denken der totalitaire staten, of die nu nationaalsocialistisch of communistisch zijn!

\section{Anticommunistisch maar Soclaal Progressief.}

Als man, die middenin het leven staat, heeft Emil Brunner zich na de oorlog bezig gehouden met verschillende actuele problemen: de doodstraf voor landverraders, die hij voorstaat, het deelnemen van christenen aan het politieke leven, dat hij propageert, en waarbij de christenen over verschillende politieke partijen verspreid kunnen zijn (een chr. partij, zoals we die in Nederland kennen en later ook in Zwitserland gekomen is, aanvaardt hij alleen als noodzakelijk in een bepaalde situatie). Terwille 
van een rechtvaardige sociale opbouw verwerpt hij zowel het liberalistische kapitalisme als het dwangcommunisme en bepleit hij een recht op privè-eigendom, dat begrensd is door het belang der gemeenschap. Brunners theologische werkgemeenschap van 140 predikanten verklaarde:

„Het is onrecht, dat enkelen in overvloed en luxe leven, terwijl anderen ondanks vlijtige arbeid het nodige ontbreekt;

het is onrecht, dat enigen door arbeidsloos inkomen een veelvoud ,"verdienen" van dat, wat anderen in het zweet huns aanschijns verwerven;

het is onrecht, dat arbeiders, die in goede tijden hun werkgevers rijk hebben gemaakt, in tijden van depressie eenvoudig op straat mogen worden gezet en daardoor steeds moeten vrezen, zonder verdienste te geraken;

het is onrecht, dat voor de kinderen van rijken alle mogelijke opleidingen open staan, terwijl begaafde kinderen van onbemiddelden deze kansen niet hebben omdat het de ouders aan geld ontbreekt of omdat zij de verdiensten van de kinderen niet kunnen missen."

Hieruit blijk dus wel heel duidelijk, dat men nog geen communist behoeft te zijn om toch tegen sociale misstanden te protesteren. Roept het Woord Gods door profeten (Amos, Jeremia) en apostelen (Jacobus) niet luide om gerechtigheid?

\section{Brunner als Prediker.}

Het wordt tijd, hier enkele woorden te wijden aan de grote plaats, die Brunner jarenlang in zijn vaderland als prediker heeft ingenomen. Elke eerste zondag van de maand preekt hij in de Fraumünster in Zürich, waar een uur voor de tijd alle zitplaatsen al bezet waren! Brunner bezit namelijk de gave, op het juiste moment het juiste woord te zeggen, waarvan ook vele zijner uitgegeven preken getuigen. Zo sprak hij in de oorlogsjaren aan de hand van de Apostolische Geloofsbelijdenis over "Christengeloof in oorlogstijd" en gaf hij ook drie preken over het eeuwige leven uit, die toen (evenals in Engeland „Brieven uit de hel” van C. S. Lewis, waarop dezer dagen een na-oorlogs vervolg verschenen is!) onielbaar velen tot steun zijn geweest. In 1953 publiceert hy voor hij vertrek naar Japan als afscheidsgeschenk voor hij Züricher gemeente de prachtige bundel „Fraumünster predigten”. Zo heeft hij ondanks zijn vele wetenschappelijke werk, toch het contact met de gemeente behouden. En zie ik in Emil Brunner een man, die met zijn nadruk op Openbaringstheologie én zijn openheid voor de moderne mens ook door zijn prediking aller aandacht verdient.

\section{JAPAN.}

Een bijzondere episode in Brunners leven en werken is wel zijn verblijf in Japan in de midden vijftiger jaren, waar hij college heeft gegeven aan de Chr. universiteit van Tokio, maar tegelijk ontzaglijk veel persoon- 
lijke contacten heeft opgebouwd. Het meest belangwekkend uit deze tijd is wel zijn tussenpersoon-zijn tussen de georganiseerde kerken en de z.g. niet-kerk-groep van christenen, welke laatse door hun informele bijeenkomsten voor bijbel en gebed grote invloed in Japan hebben. Brunner kent zowel de gevaren van de georganiseerde kerk als die van de vrije buitenkerkelijke christengroepen en wist door zijn openheid voor beide heel wat tegenstellingen te overbruggen. Zijn werk in Japan vond zoveel waardering, dat de keizer zelf hem opriep, toch vooral zijn werk in Japan voort te zetten.

\section{Drie Delen Dogmatiek.}

Een hoogtepunt van Brunners schrijverswerkzaamheid is wel het verschijnen van zijn driedelige Dogmatik (1946, 1950, 1960), waarin wij de grondgedachte, die Brunner reeds in zijn „Wahrheit als Begegnung” gaf: dat de waarheid Gods voor ons tot levende werkelijkheid wordt in de persoonlijke ontmoeting tussen God en mens. Ik voel hier het levende dogmatiseren van éen, die zelf door schuldbelijden en boete tot geloofsgehoorzaamheid aan Christus kwam en dus ook al zijn verstandelijke gaven in dienst stelt van zijn Heer.

Wat de verhouding van Brunners tot Barths theologische gedachten betreft, valt ons op, dat Brunner het met Barth eens blijkt te zijn op punten, waar wij dit niet zouden verwachten - b.v. ten aanzien van de door Barth in zijn Dogmatik 3-1 voorgedragen gedachten over ,natuurlijke theologie"), maar ook, dat Brunner het met Barth oneens is op verschillende andere punten. Het is vanuit Brunners waarheidsopvatting wel duidelijk, dat hij critiek zal oefenen op Barths té zeer vereenzelvigen van geloof en theologie, wat dan ook in 1-pag. 72 geschiedt. Scherp wordt deze critiek echter, waar Barth in zijn uitverkiezingsleer Christus tegelijk makt tot de alleen uitverkiezende God en de enig uitverkoren mens, hieraan toegevoegend, dat ,Jezus de eeuwig uitverkoren mens is, de praeëxisterende Godmens, Die als zodanig de grond aller verkiezing is". Hierdoor acht Brunner het Kersfeest van het wonder beroofd. En als Barth verder schrijft dat Jezus Christus behalve de enig uitverkorene ook de enige verworpen mens is en schrijft „,buiten Jezus Christus is er geen verworpene", verklaart Brunner dit resoluut voor onbijbels. Want de Bijbel leert, dat er geen verdoemenis is voor degenen, die in Christus Jezus zijn, maar dat er ook is een brede weg, die naar het verderf leidt. Hier laat Brunner wel heel andere klanken horen dan Barth, ook al is en blijft hun beider streven en hoofdaccent: theologie is enkel en alleen openbaringstheologie, dezelfde.

Het zou in dit toch al zo lang geworden artikel te ver voeren, hierna nog uitvoerig in te gaan op alle rijke gedachten van deel 2 en 3 . Slechts zij aangestipt het grote accent, dat Brunner in deel 2 legt op het subjectieve handelen Gods in de verzoening. Deel. 3 is dan de uitwerking van twee 
voorstudies „Das Misverständnis der Kirche” (historische uiteenzetting van het verval der oerchristelijke gemeente als organisme tot de organisatie der kerk, het ergst bij de R.K. - met oproep tot bekering tot her oerchristelijk gemeente-zijn) en „Das Ewige als Zukunft und Gegenwart”, waarin Brunner het sterven, het „uit de tijd gaan”, in het eeuwig nu der eeuwigheid als de tijd opgehouden is laat samen vallen met de opstanding.

\section{SLOTWOORD.}

Mogen velen uwer zich door deze inleiding tot een nadere kennismaking met Brunners werken gedrongen voelen; naar mijn vaste overtuiging zal deze theologie juist voor Suid-Afrika met al zijn vragen en problemen zeer veel kunnen betekenen - als men in de van God gegeven ordeningen gaat zoeken naar het gebod van het uur, dat Gods Geest duidelijk wil maken aan hen, die Hem gehoorzaam zijn.

G. J. H. Gijmink. 